\title{
Fuel consumption and emission on fuel mixer low-grade bioethanol fuelled motorcycle
}

\author{
Setia Abikusna*, Bambang Sugiarto, and Azami Zulfan \\ Mechanical Engineering Department, Faculty of Engineering, Universitas Indonesia, Depok 16424, Indonesia
}

\begin{abstract}
Bioethanol is currently used as an alternative fuel for gasoline substitute (fossil fuel) because it can reduce the dependence on fossil fuel and also emissions produced by fossil fuel which are $\mathrm{CO}_{2}, \mathrm{HO}$, NOx. Bioethanol is usually used as a fuel mixed with gasoline with certain comparison. In Indonesia, the usage is still rare. Bioethanol that is commonly used is bioethanol anhydrous $99.5 \%$. In the previous studies, bioethanol was distilled from low to high grade to produce ethanol anhydrous. But the result is only able to reach $95 \%$ or ethanol hydrous. This study is objected to design a simple mechanism in the mixing of bioethanol hydrous with the gasoline using a fuel mixer mechanism. By this mechanism, the fuel consumption and the resulting emissions from combustion engine can be analyzed. The fuel blend composition is prepared as E5, E10, and E15/E20, the result of fuel consumption and emission will be compared with pure gasoline. The using of bioethanol hydrous as a fuel mixture was tended to produce more stable bioethanol fuel consumption. However, the utilization of the mixture was found able to reduce the exhaust emissions (CO, $\mathrm{HC}$, and $\mathrm{NOx})$.
\end{abstract}

\section{Introduction}

The requirement of energy is the problem that is faced by all countries in the world, including Indonesia. Energies which are often used dominated by fossil energy, which are: petroleum, natural gas, and coal. Especially for petroleum, it is still a source that dominates energy requirement in most of the countries. Indonesia is one of the countries, which consumes crude oil as a primary fuel. In 2013, the using of fuel oil in Indonesia had achieved almost $46,1 \%$. By comparing the percentage of other energy need sources, the using of fuel oil is the most profoundly of all, followed by using gas fuel and coal [1].

High fossil fuel requirement relates to the using of the vehicle. In this modern era, the human is easy to obtain any means of transportation, in this case, is motor vehicles where human highly counts on them. This issue has become the main factor of the highest utilization of fossil fuel, especially in Indonesia. Jakarta is one of the cities in Indonesia, which has the highest motor vehicles growth number. We are able to see the condition from the increasing number of motor vehicles in Jakarta. In 2014, the utilization of motor vehicles reached at 17.423.967 in Jakarta. Its growth is $9,93 \%$ per year [2]. It signifies the dependence on fossil fuel getting higher. The lack of fossil energy source, namely petroleum, and the requirement of fuel vehicles keeps increasing; consequently, it causes renewable energy development which is non-fossil energy to be severely required.

One of the alternative solutions is biomass energy whether it is in pure form or mixed with fossil fuel. It is one attempt to reduce the very high fossil fuel consumption.

One of biomass utilization technology results which can be used as an alternative fuel or as a mixture of gasoline on motor vehicles is anhydrous bioethanol, it's preferred because of its less water content, moreover, it is able to be mixed homogeneously with gasoline. Either bioethanol anhydrous or bioethanol hydrous can be mixed. The problem is the low percentage of bioethanol hydrous and less water content, however, it is not able to be directly mixed with gasoline because of its water content causes the non-homogeneous mixture. Thus, bioethanol hydrous usually has water content about 4 , $9 \%-5 \%$, where gasoline water content in maximum is about 7, 4\%.

Based on previous research, it discussed about a mixing mechanism between bioethanol anhydrous and gasoline by using mechanism fuel mixer into the combustion chamber through the opening valve. The problem of using bioethanol hydrous as fuel is its low exploitation. Besides, its influence on the machine performance has not been shown widely. Hence, the researcher of this advanced research is focussing the investigation on finding out the performance of fuel consumption in the dynamic loaded motor by using mixing gasoline mechanism with $96 \%$ bioethanol hydrous using fuel mixer.

This research has been conducted for finding out the machine performance of fuel consumption in a dynamic condition from a loaded motor vehicle and mixed fuel between gasoline and bioethanol by controlled ratio.

Corresponding author: setia.abikusna@gmail.com 


\section{Research methodology}

\subsection{Valve opening controller}

Taking calibration data, firstly, it is determined in the preliminary data that it is used in the calculation of calibration result. Data are:

- Source speed data from hair dryer or air $\left(\mathrm{V}_{\mathrm{in}}\right): 16.68$ $\mathrm{m} / \mathrm{s}$ (air speed flows into carburetor as effect of combustion chamber inhaling )

- Large of A outlet (pipe diameter, $d=0.01905 \mathrm{~m}$ ) : $0.00028 \mathrm{~m}^{2}$.

The pipe used is a $43.7 \mathrm{~cm}$ long, the measuring was conducted when the current has been fully developed. It concerns that flow rate profile is easier to be drawn and more accurate when it is measured after it is fully developed. Conducting measurement with the mechanism will also be minimized any error that occurs at real speed value [3]. To detect whether flow exhaustion is fully developed is by its appropriation with Reynold number of the fluid that flows. Its fluid is air which has a density equal to $1.2 \mathrm{~kg} / \mathrm{m}^{3}$ and viscosity equal to $0.000018 \mathrm{~kg} / \mathrm{m}$.s. Reynold number equal to $\rho \mathrm{VD} / \mu=20266$. The flow is turbulence so to determine the length of it has to be in fully developed condition by the formula $\left.\left[1 \mathrm{e}=\mathrm{Dx} 4.4(\mathrm{Re})^{1 / 6}\right)\right]$ and the value equals to $0.437 \mathrm{~m}=43.7 \mathrm{~cm}$. The distance of pipe will be able to used to measure the flow rate.

Then preliminary assumption for calibration data that will be used for calculation is as follow:

- Assumption $V_{\text {in }}=V$ (to gasoline carburetor venture)

$=\mathrm{V}_{\mathrm{b}}$ (gasoline vapor)

- Assumption gasoline vapor debit rate

$\mathrm{Q}=\mathrm{A} \times \mathrm{V}_{\text {in }}=0.00467 \mathrm{~m}^{3} / \mathrm{s}$

Then, to get a comparison between bioethanol volume equal to $5 \%, 10 \%$ and $15 \%$ from the total volume mixture of bioethanol and gasoline, needed precise bioethanol vapor flow rate data.

Taking calibration data is conducted by flowing gas source from hairdryer then attends to speed value and pressure drop in every valve-opening $0^{\circ}$ until $450^{\circ}$. We can refer to that appropriate speed to get a comparison between bioethanol hydrous E5, E10, and E15 is in valve-opening $180^{\circ}, 240^{\circ}$, and $310^{\circ}$. Here, this valveopening becomes the controller when taking the real testing data.

\subsection{Fuel mixer installation}

In this study, the installation of fuel mixer and check on the condition of the machine were conducted; whether the machine runs properly or had trouble, in order to avoid the disorderly when data retrieval took place. Fuel mixer is able to be seen as the figure below.

Fuel mixer was mounted with two carburetors on the right and the left side. Both of them had the function to deliver the fuel to the combustion chamber. The fuel in both of carburetors could be delivered and atomized into the combustion chamber. Fuel was separated in each valve of gasoline and bioethanol. An instrument on the valve that is functioned to regulate the amount of bioethanol insertion whether it is an appropriate amount or not is needed.

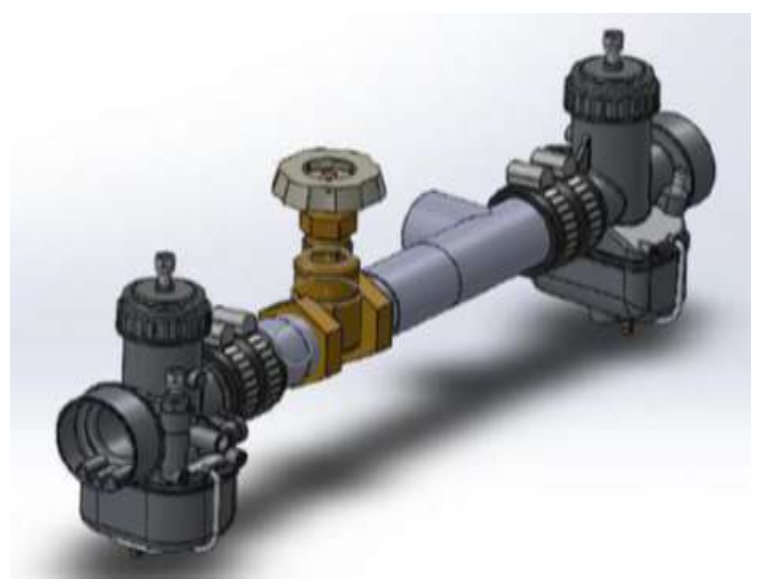

Fig. 1. Fuel mixer

\subsection{Variable testing}

The variables were used in this research, namely:

Fixed Variables

- Motorcycle test

- Trajectory and distance test.

- Motor speed

Independent Variable

- Utilized Fuel mixture composition of bioethanol and gasoline

Dependent Variables

- Fuel consumption volume.

- Process data of fuel consumption.

\subsection{Limited problems}

Limitations which were used in research namely:

- Using dynamic motor fuel namely Suzuki Thunder 4 stroke 125 cc motorcycle, produced in 2007 and the condition was good about $70 \%$.

- All capacities of each carburetor were considered equal,

- The phase for both of fuels which delivered into the combustion chamber was considered one phase, that is gas.

- Setting speed from bioethanol carburetor and its capacity were controlled by a gate valve.

- Bioethanol which was used, namely $96 \%$ bioethanol hydrous.

- Testing was conducted on dynamic condition (had running load) based on SNI 09-4405-1997(the durability test) and SNI 06-3763-1995 (the stability test).

- Dynamic testing was conducted at a constant velocity, $30 \mathrm{~km} /$ hour by tolerance about $\pm 5 \mathrm{~km} /$ hour.

- The analysis was only focused on the machine performance result, that is fuel consumption to an addition of bioethanol hydrous as fuel. 


\subsection{Procedure of taking data}

The following will explain the procedure of the fuel consumption data based on SNI 09-4405-1997 and SNI 06-3763-1995:

1. To prepare bioethanol and gasoline is by measuring the volume with measuring cup, then bring it to the bottle (tank) which had been connected to the carburator.

2. To ignite motorcycle test.

3. To prepare stopwatch for measuring traveling time.

4. To start taking data of motor vehicle dynamic test for the distance about $100 \mathrm{~km}$ to SNI 094405-1997, $300 \mathrm{~m}$ and $500 \mathrm{~m}$ to SNI 06-37631995 with constant speed about $30 \mathrm{~km} / \mathrm{hour}$ (tolerance $\pm 5 \mathrm{~km} /$ hour).

5. To fill the fuel addition which its volume had been measured (if needed).

6. To measure the residue in order to get consumption volume.

7. To repeat the data collection by opening valve about $180^{\circ}, 240^{\circ}$, and $310^{\circ}$ for obtaining ratios for E5, E10, and E15.

\section{Result and discussion}

\subsection{Fuel consumption}

On the durability test was obtained the result of fuel consumption using fuel mixture mechanism to mix fuel between bioethanol and gasoline. This test was based on SNI 09-4401-1997 with constant speed $30 \mathrm{~km} / \mathrm{hour}$ (tolerance $5 \mathrm{~km} /$ hour) on 4 fuel conditions, $5 \%$ bioethanol hydrous, $10 \%$ bioethanol hydrous, and 15\% bioethanol hydrous, and using pure gasoline. Testing result is shown in the table below:

Table 1. Testing result

\begin{tabular}{|c|c|c|}
\hline Type of fuel & $\begin{array}{c}\text { Timing test } \\
\text { (hour) }\end{array}$ & $\begin{array}{c}\text { Fuel consumption volume } \\
\text { (L) }\end{array}$ \\
\hline E0 & 3,74 & 4,34 \\
\hline E5 & 3,69 & 4,05 \\
\hline E10 & 3,71 & 3,90 \\
\hline E15 & 3,72 & 3,55 \\
\hline
\end{tabular}

As shown in table 1. that data would be processed in order to get fuel consumption value for each type of fuel. The formula to measure fuel consumption is:

$$
F C=\frac{V f \times 3600}{t \times 1000}
$$

where:

$$
\begin{aligned}
\mathrm{FC} & =\text { fuel consumption }(\mathrm{l} / \mathrm{h}) \\
\mathrm{Vf} & =\text { fuel consumption at } 1 \mathrm{sec}(\mathrm{ml}) \\
\mathrm{t} & =\text { time }(\mathrm{s})
\end{aligned}
$$

Based on the result of calculation from above formula accordingly, the result of fuel consumption, green line for pure gasoline, which is shown in the graph below:

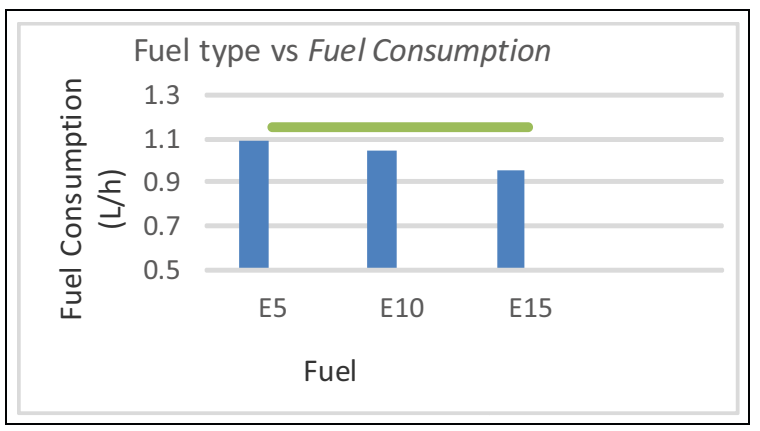

Fig. 2. Fuel consumption vs fuel type

As seen on Table 1, the fuel consumption value for each sort of test fuel was presented. Based on the graph shown in Fig 2., the fuel consumption value for fuel E15 is definitely lower than another fuel. The fuel consumption of E15 equals to $0,95 \mathrm{~L} /$ hour. From that graph, the consumption of pure fuel was found higher than fuel consumption value of mixed fuel between bioethanol and gasoline. It can be explained that requirement of bioethanol in mixture fuel causes lower fuel consumption or more economical than using pure gasoline. It is occurred because bioethanol has lower heating value than gasoline; therefore, it may increased thermal efficiency. The increase in thermal efficiency is commonly due to higher flame speed of the fuel than bioethanol. Consequently, the higher content of bioethanol in the mixture the more efficient in engine operation will be occurred. The increasing of efficiency was in contrast to fuel consumption value; furthermore, it could be said more economical.

The stability test results in the form of fuel consumption using fuel mixer mechanism to mixture fuel between bioethanol and gasoline. This test was conducted based on SNI 06-3763-1995 with the distance of $300 \mathrm{~m}$ and $500 \mathrm{~m}$ at a constant speed of $30 \mathrm{~km} /$ hour (tolerance $5 \mathrm{~km} /$ hour) at 4 fuel conditions, which are $5 \%$ bioethanol hydrous, $10 \%$ bioethanol hydrous, $15 \%$ bioethanol hydrous, and pure gasoline. Testing results are mentioned in figures below:

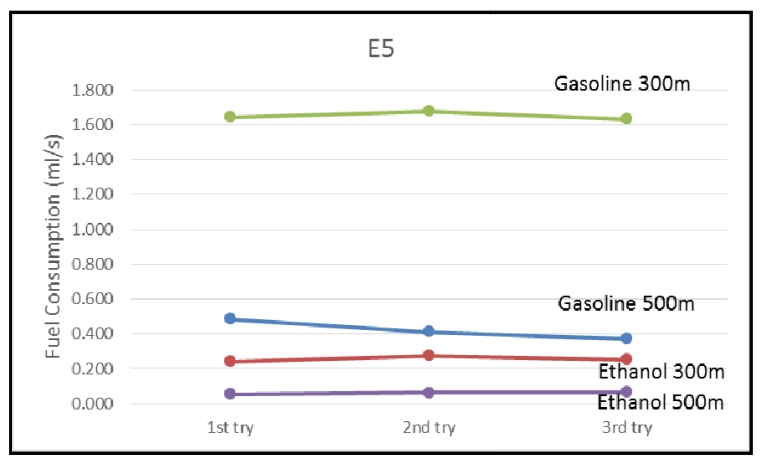

Fig. 3. Fuel consumption E5 


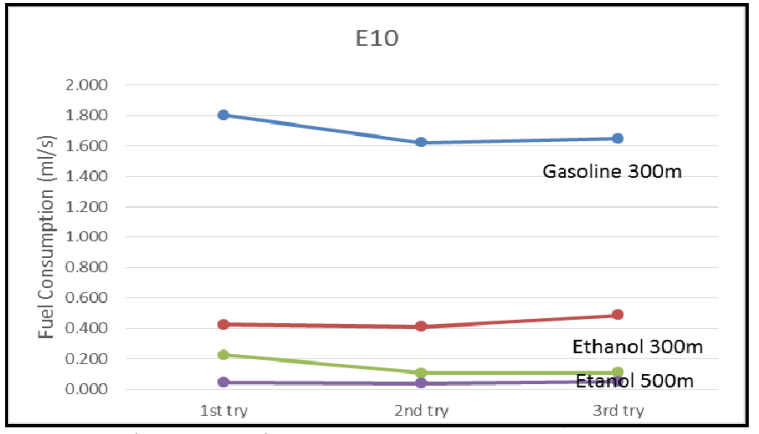

Fig. 4. Fuel consumption E10

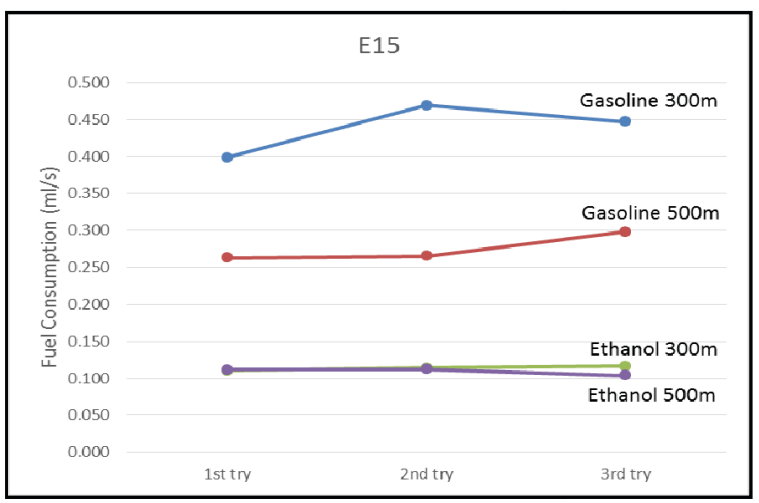

Fig. 5. Fuel consumption E15

From the results of the test, fuel consumption values became greater by using bioethanol hydrous as a fuel mixture than pure fuel gasoline. The higher fuel consumption is effected by the water content in bioethanol hydrous. Therefore, more fuel are needed to complete combustion. In E15, it is noted that bioethanol content is more than enough to assist water combustion in the combustion chamber and also because flame speed is higher by high bioethanol, thus, unburden fuel become less than other fuel mixture variations.

From the three of fuel mixtures, E15 is a fuel mixture with more stable fuel consumption. It is precisely shown from the ratio of fuel consumption in each test and each interval variation for bioethanol fuel blends.

\subsection{Emission}

The higher content of $\mathrm{CO}$ in the exhaust gasses of combustion shows an incomplete combustion. In Figure 8 , it is shown that there are large contents of $\mathrm{CO}$ (between 2.5\% - 3\%) when the system used the gasoline fuel without bioethanol mixture. It shows that the air and fuel mixture is lower compared to fuel that has been mixed with bioethanol. It can be seen that the more addition volume of bioethanol, the lower content of $\mathrm{CO}$ generated. The lowest $\mathrm{CO}$ content is in the addition of bioethanol about $20 \%$ that could lower $\mathrm{CO}$ gas emission until $0.1 \%$ at $5.000 \mathrm{rpm}$. This is because the ethanol has -OH molecule that helps to boost the occurrence of the perfect combustion reactions. The more fuel that binds oxygen could trigger the process of oxidation so that $\mathrm{CO}$ can be turned into $\mathrm{CO}_{2}$.

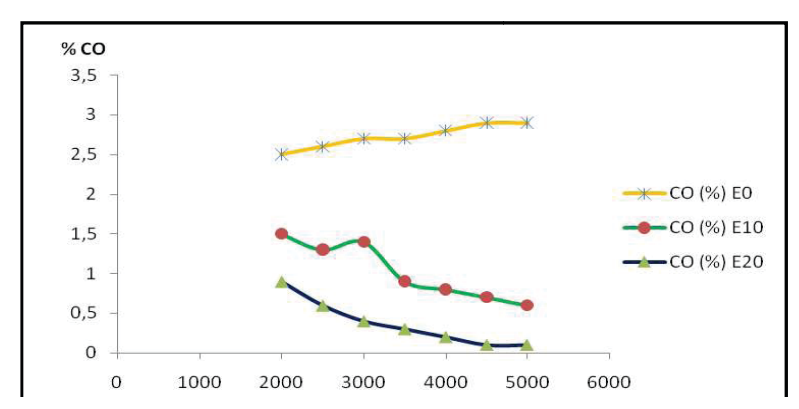

Fig. 6. $\mathrm{CO}$ vs engine speed

The levels of $\mathrm{CO}$ and $\mathrm{CO}_{2}$ is found very close. A declined levels of $\mathrm{CO}$ in exhaust emissions will increase the level of $\mathrm{CO}_{2} \cdot \mathrm{CO}_{2}$ is the combustion reaction product components. In other words, the $\mathrm{CO}_{2}$ is a gas that is more desired from any combustion reaction product rather than $\mathrm{CO}$. The higher level of $\mathrm{CO}_{2}$ in the system is an indicator of a perfect combustion. It is due to the oxygen molecule $-\mathrm{OH}$ in ethanol will join in the exhaust of $\mathrm{CO}$ so that it will generate more $\mathrm{CO}_{2}$ emissions, as shown in Fig. 7.

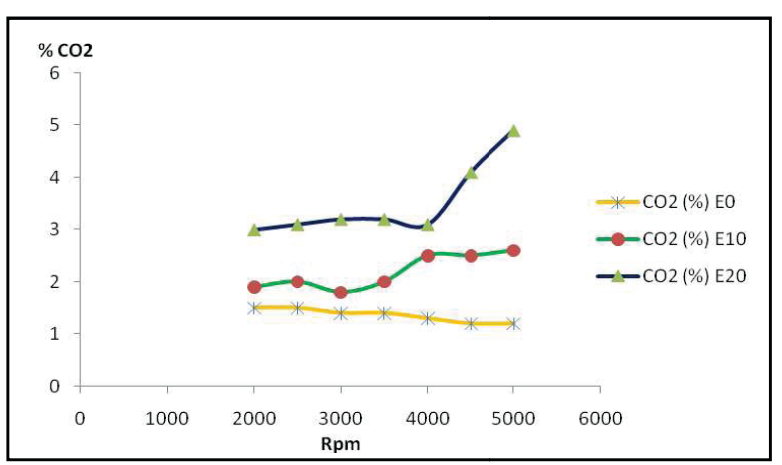

Fig. 7. $\mathrm{CO}_{2}$ vs engine speed

More ethanol in fuel mixture was clearly performing an increased in the $\mathrm{CO}_{2}$ products in exhaust gas as the increased in engine speed as well.

When gasoline vapor is heated at high temperature, oxidation will promoted to occured, the consequence is incomplete combustion. This unburned gasoline is produced from combustion chamber as unburnt hydrocarbon (HC) gasses.

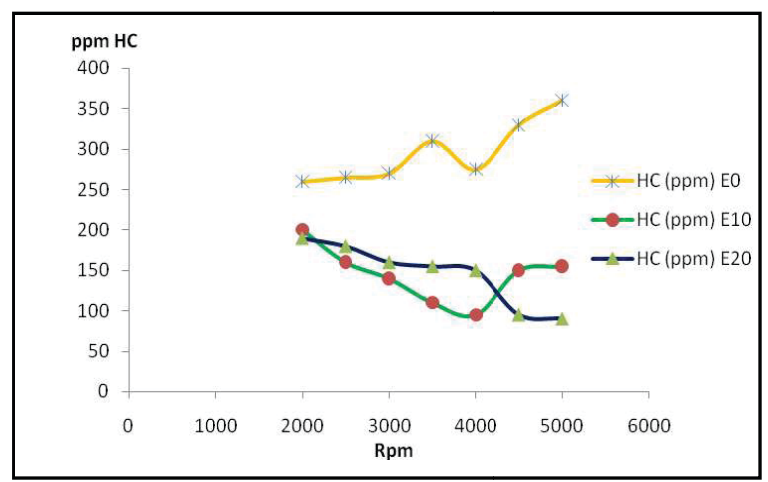

Fig. 8. $\mathrm{HC}$ vs engine speed 
In Fig. 8, it is shown that the addition of bioethanol give insignificant changes in the $\mathrm{HC}$ exhaust emissions. A variations in engine speed fuelled with E10 and E20 performing the uncertain trend in $\mathrm{HC}$ emissions. While the usage of E0 caused an increase in $\mathrm{HC}$ emissions with the increase of engine speed.

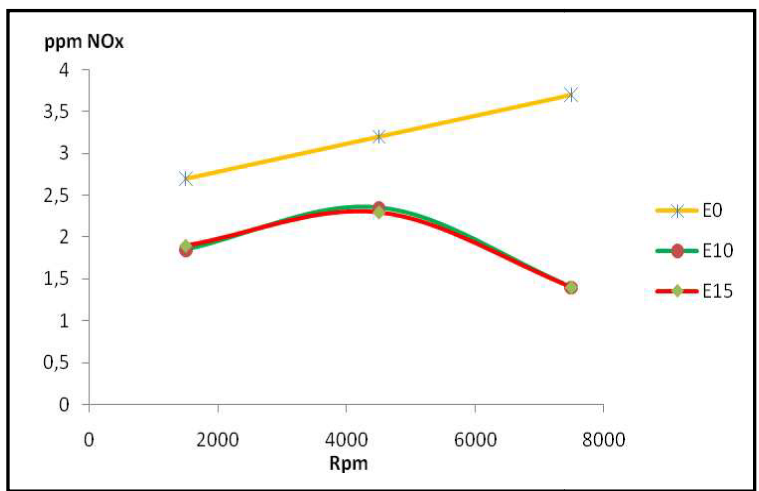

Fig. 9. NOx vs engine speed

The effect of engine speed variations on NOx emission was shown in Fig 9. In general, the addition of ethanol in fuel was extremely performing a lower NOx emissions. It was found reduced to $42 \%$ compared to the effect in using of gasoline as fuel. This is due to ethanol has a higher heating value than gasoline. That energy is used to evaporate the ethanol for a better combustion process, As the consequences, the exhaust gas temperature will be lower and so the formed NOx in the exhaust gas will be reduced.

\section{Conclusion}

Based on the data from the testing result, the higher bioethanol contents in fuel mixture with gasoline accordingly, the lower fuel consumption value of fuel mixture. The using of bioethanol hydrous as a fuel mixture produces more stable fuel consumption compared to pure gasoline. The addition of bioethanol, in general, is also able to decrease the exhaust emissions $(\mathrm{CO}, \mathrm{HC}$, and NOx). From the test in this study, the increase in $\mathrm{CO}_{2}$ content in the exhaust gas is confirmed as the occurrence of a complete combustion. The $\mathrm{CO}_{2}$ levels were relatively increased by the increase of engine speed in each of fuel mixtures.

\section{References}

1. Pusdatin Kementrian Energi dan Sumber Daya Mineral, Handbook, (2014)

2. Badan Pusat Statistik Indonesia (2015)

3. M. Ghazikhani, M. Hatami, B. Safari, D. Domiri Ganzi, Case Studies in Thermal Engineering, 2, 8290 (2014)

4. B. Sugiarto, Y. Whulanza, Report, Universitas Indonesia (2014)

5. A.S. Kyriakides, L. R. Gracia, S. Voutetakis, D. Ipsakis, P. Seferlis, S. Papadopoulou, Fuel 108 208215 (2013)
6. R. Munsin, Y. Laoonual, S. Jugjai, Y. Imai, Fuel Fuel 106 586-592 (2013)

7. C. Tadeu, C. de Melo, G. B. Machado, C.R.P. Belchior, M..J. Colaço, J.E.M. Barros, E. J. de Oliveira, D. G. de Oliveira, Fuel 97 796-804 (2012)

8. R. C. Costa, J. R. Sodre, Jose, Fuel 89 287-293 (2010)

9. D. Turner, H. Xu, R.F. Cracknell, V. Natarjan, X. Chen, Fuel 90 1999-2006 (2010)

10. Y.C. Yao, J.H. Tsai, I.T. Wang, International Journal of Applied Energy, Applied Energy, 102 93100 (2013)

11. M. Koç, Y. Sekmen, T. Topgül, H. S. Yücesu, Renewable Energy 34 2101-2106 (2009)

12. I. Schifter, L. Diaz, R. Rodriguez, J.P. Gómez, U. Gonzalez, Fuel 90 3589-3592 (2011) 